\title{
Toxic polyneuritis in Bombay due to ortho-cresyl-phosphate poisoning
}

\author{
D. D. VORA, DARAB K. DASTUR, BEATRIZ M. BRAGANCA, L. M. PARIHAR, \\ C. G. S. IYER, R. B. FONDEKAR, AND K. PRABHAKARAN \\ From Lokmanya Tilak Municipal General Hospital, Sion, Neurology Unit, Indian Council of Medical \\ Research, and Department of Enzyme Chemistry, Indian Cancer Research Centre, Bombay
}

Since 1930 poisoning with ortho-cresyl-phosphate has been recognized as a cause of peripheral polyneuritis (Smith, Elvove, and Frazier, 1930). Orthocresyl-phosphate (O.C.P.) is widely used as a plasticiser and in the production of heat-stable lubricating oils. Many cases of industrial poisoning with O.C.P. have been reported since then but as a result of strict precautionary measures it has now become a rarity. However, the occasional contamination of food with O.C.P. is not uncommon.

Poisoning with O.C.P. was first reported in patients with pulmonary tuberculosis who underwent treatment with phospho-creosote (Hunter, 1956), and physicians became well versed in the clinical picture of poisoning with O.C.P. after the outbreak of polyneuritis, described as 'Jamaica ginger paralysis' which occurred in the U.S.A. in 1930 (Burley, 1932). A similar picture appeared in Holland in women who used Apiol (containing O.C.P.) as an abortifacient (Guttmann, 1932). In 1937, there was an outbreak of sudden peripheral polyneuritis in Durban, produced by the use of Bestol superfine cooking oil. This was subsequently traced to the original oil which had been sent from England in large drums previously used for storing lubricating oil containing O.C.P. (Sampson, 1942). Humpe (1942) reported five cases of peripheral polyneuritis caused by the accidental consumption of fat contaminated with O.C.P. An outbreak of the characteristic polyneuritis due to O.C.P. occurred in Morocco, when about 10,000 persons were affected, and the source was traced to a lubricant which had been used to adulterate the cooking oil (Smith and Spalding, 1959).

\section{EPIDEMIOLOGY}

On 12 January 1960 a man living in the Mahim area of Bombay city was admitted to Lokmanya Tilak Municipal General Hospital with characteristic peripheral polyneuritis. He mentioned that several of his room-mates were similarly affected. They purchased food from the same grocer in their neighbourhood. He also mentioned that others staying in the same locality and consuming mustard oil, but purchasing their food from other grocers, were not affected. The examination of the other affected persons revealed identical histories and clinical pictures. In this group there was no history of gastro-enteritis or of febrile illness preceding the paralysis. These patients also asserted that all those who were buying their food from the same grocer but who were not consuming mustard oil were unaffected and led one of us (D.D.V.) to suspect strongly some toxic factor in mustard oil as the responsible agent. Thereupon an epidemiological investigation was begun. A note was issued to the local press on 19 January 1960 advising consumers of mustard oil to be cautious, as illness was suspected to arise from its consumption. A week later, another similar outbreak was reported from another part of Bombay (Dharavi area), where more than 30 persons were affected. Twenty of them were subsequently admitted to Lokmanya Tilak Municipal General Hospital.

Further investigation of the patients and residents of the localities in which these patients resided led to the inference that only those who consumed mustard oil (all from the state of Uttar Pradesh) and belonging to a very low income group (hawkers, washermen, and textile weavers) suffered from the disease. Individuals belonging to different communities and having different food habits, though residing with the patients in adjoining rooms, remained unaffected. This ruled out the possibility of infection as the aetiological factor.

Samples of food (including a large number of edible oils) were taken for analysis from shops in the localities where the two outbreaks occurred, as well as from the wholesale dealers who supplied edible oils to retail grocers in the affected areas. All patients belonged to low income groups and were known to buy their food in daily rations so it was not possible to obtain samples of oils consumed by the patients. Neither O.C.P. nor any toxic factor 
could be detected on analysis of samples of oil obtained from shops in these areas. A few of the samples of oil collected some time after the outbreak of the epidemic were found to contain very small concentrations of phenol and phosphates, presumably derived from O.C.P.

On 9 May 1960 (four months after the previous outbreaks), two patients with a similar peripheral polyneuritis and with identical histories, coming from the Mahim area of Bombay, were admitted to Lokmanya Tilak Hospital. It was observed that all the cases from the Mahim area admitted in January and in May 1960 had purchased their mustard oil from the same grocer. Three hundred and forty-four samples of oil were collected and examined between May and July 1960. Ortho-cresyl-phosphate was detected in 49 of these samples, the concentration varying from $0.65 \mathrm{mg}$. to $32.5 \mathrm{mg}$. per $100 \mathrm{~g}$. of oil. It is interesting to note that four samples of oil collected from one wholesale dealer in Bombay were found adulterated with 2 to $12 \%$ of mineral oil containing ortho-cresyl-phosphate.

The total number of cases recorded in the city was 58 (53 men and five women). Thirty-two patients were studied in hospital ( 29 men and three women), and of these, 29 were admitted in January 1960, one in February, and two in May.

It is worth noting that the patients in this series were individuals whose families were not residing in Bombay. The majority (27) were males in the agegroup 11 to 40 years. This explains the higher incidence of males in the present series as contrasted with the age and sex distribution in the Morocco epidemic (Smith and Spalding, 1959). Thirty-one of the patients used mustard oil for cooking and for massaging the body. One patient denied emphatically having used mustard oil for cooking and insisted that he used it only for massaging the body. None of the patients came in contact with O.C.P. as a result of his occupation.

\section{CLINICAL FEATURES}

HISTORY All the patients had been using mustard oil for cooking and massaging their bodies for years. They did not observe any significant change in the appearance, taste, or smell of the oil at any time. It was therefore not possible to establish the interval between the consumption of the toxic factor in the oil and the onset of paraesthesiae. Nine persons reported the history of diarrhoea with or without griping abdominal pain a few days before the onset of illness. None of them had fever preceding the illness, except one case of extensive bilateral pulmonary tuberculosis.

Twenty-three patients reported either a continuous cramp-like pain or heaviness in the calves before the onset of paralysis. Of these, 17 also complained of paraesthesiae. The same symptoms were referred to the upper extremities in nine of the 23 patients. Commonly, paresis of the legs developed within 12 hours of onset of pain or paraesthesiae, followed within 12 to 36 hours by paresis of the hands. The pain subsequently disappeared within four days in the majority of patients. Patients who were emaciated or in poor health were the worst affected. The patient with pulmonary tuberculosis was more severely paralysed than others.

On examination the abnormal findings were confined to the nervous system. The motor system was most affected. The muscles of legs were more severely affected than those of the hands and forearms. In 20 patients power was severely reduced, six of these being completely paralysed at the wrists also. Thirty patients were paralysed at the toes and ankles. The dorsiflexors and everters of the feet were maximally involved, causing foot drop. There was only a mild to moderate degree of weakness of muscles acting on the knee and elbow joints. Tone was diminished in varying degree in all except two cases. This diminution was symmetrical in distribution and was more in the distal segments of the limbs. In many patients, the biceps and knee reflexes were exaggerated in spite of diminished tone, wasting, and a plantar flexor response.

Sensations of touch, pain, and temperature in 27 patients were impaired, this being of 'glove and stocking' distribution. The lower limbs were usually more affected than the upper. There was anaesthesia of palms and feet in five patients. Joint sense was normal in all except one patient, in whom it was unilaterally affected. The vibration sense was diminished in four patients in the lower limbs only.

All patients had a high-stepping gait associated with tilting of the pelvis on alternate sides. This gait was so characteristic that in the Medical Outpatient Department even the orderlies diagnosed the entering patients as those having telwali bimari (illness of oil). None of the patients could stand steadily on one spot without support. When required to stand without support, they alternately lifted the legs as if marching. It was curious that even though they could not stand, they were able to run fast with a high-stepping gait and jump well enough to play volley-ball unaided. None of these patients could eat properly with their hands and fingers (in the Indian style) nor could they hold the spoon. Initially they had to be fed by others. When asked to eat by themselves, they held the morsel in the palm, with the fingers and thumb flexed at the interphalangeal joints and ate directly from the palm. This finding was seen in all the cases. 
At a subsequent neurological examination three to four weeks later, an increase in the weakness of the limbs, persistence of the sensory impairment, and tenderness of the calves were observed in most of the patients.

Attempts were made to rehabilitate them by physiotherapy and occupational therapy. Each patient was given daily injections of thiamine hydrochloride (100 mg.) and cyanocobalamine (100 $\mu \mathrm{g}$.) intramuscularly. Improvement was very slow. Except for four patients who remained in the hospital for about six months, all sought discharge against medical advice within two weeks of admission. They showed progressively a fair degree of gain in power of the affected muscles, sufficient to enable them to return to their respective occupations. One of them was a weaver requiring dextrous finger movements to work on automatic looms. These patients appeared to have benefited from physiotherapy and occupational therapy.

CLINICAL INVESTIGATIONS The routine investigations at the time of admission revealed the following salient featu res. Eighteen cases showed a mild degree of anaemia. The white cell count was more than $10,000 / \mathrm{c} . \mathrm{mm}$. in four cases, was less than $5,000 /$ c.mm. in two cases, and in the rest it was between $5,000 / \mathrm{c} . \mathrm{mm}$. and $9,000 / \mathrm{c} . \mathrm{mm}$. Examination of the stool samples revealed cysts of Entomoeba histolytica in three, ova of Ankylostoma duodenale in two, ova of Ascaris lumbricoides in two, and ova of Hymenolepis nana in one. Urine analysis (all cases), cerebrospinal fluid examination (15 cases), and gastric analysis (seven cases) revealed nothing abnormal. The blood Kahn test was negative in all cases. An E.C.G. was recorded in 12 cases. Eight cases showed findings within normal limits, and four showed minor abnormalities. Virological investigations on stool samples, throat washings, and blood sera were negative.

DISCUSSION All patients investigated in this study showed clearly the symptoms of acute peripheral polyneuritis from the onset, with overwhelming affection of distal segments of the limbs. The clinical picture in the present study was clearly suggestive of O.C.P. poisoning.

Epidemiological data indicated that O.C.P. present as a contaminant in mustard oil used for cooking was the responsible toxic material. A third of the patients had consumed the oil purchased from one shop only, and it is significant that those who consumed food other than mustard oil bought in that particular shop remained unaffected. The patients studied all belonged to the lower economic strata known to purchase their articles of food in daily rations. This could account for the failure to $\underline{0}$ demonstrate O.C.P. by analysis in samples of oil $Z$ collected a few days after the outbreak from the patients' houses. It is important that 49 out of 344 o samples of mustard oil collected during one period $\underset{0}{C}$ from various dealers in the city were found to con- 0 tain ortho-cresyl-phosphate.

According to the literature (Hunter, 1955; Jordi, 六 1952; Burley, 1932) symptoms of O.C.P. toxicity appear between five and 21 days after absorption of the toxic material. For the first day or two persistent $\overrightarrow{\vec{A}}$ gastrointestinal symptoms are known to occur in $\stackrel{5}{\circ}$ the form of abdominal pain, nausea, vomiting, and $\frac{2}{\circ}$ diarrhoea (Hotston, 1946) but the diarrhoea and $\frac{\bar{c}}{\omega}$ griping abdominal pain experienced by some of the $\frac{\vec{D}}{\vec{D}}$ patients of this series could not be attributed to the $\varrho$ toxic effects as many of them showed ova and/or is cysts of several pathogenic organisms in the stools. $\vec{O}$

Reports of the Morccco epidemic (Smith and Spalding) include bradycardia and fever among the $\vec{\omega}$ manifestations. In the present series, none of the patients had fever but five of the 32 manifested bradycardia. During the first two or three weeks in after the onset of paralysis in the lower limbs, hyper- or hidrosis, cyanosis, mottling, or coldness of the legg in were noted by Burley. None of the cases of this present series showed these signs.

The pain and paraesthesiae of calf muscles at the onset of the disease are, after about two days generally followed by weakness of muscles of the feet and hands. In a small number of cases a interval of 10 days has been reported between $\vec{B}$ involvement of the feet and hands (Hunter, 1956) In the present study the interval between the onset of pain and weakness was much shorter (less than 12 hours) and the maximum interval between affection of the feet and hands was 36 hours. The sensory involvement was more significant in the present series compared with the reports from Morocco. On the other hand, signs suggestive of involvement of pyramidal and spinocerebellar tracts reported from Morocco were not detected in the present study.

\section{HISTOPATHOLOGICAL FINDINGS}

MATERIAL AND METHODS These findings are based on a study of specimens of skin of the calf and of the gastrocnemius muscle, removed at operation from 14 of the 32 patients admitted to hospital. (Adequate muscle tissue was available for examination in only 11 of these.) Formalin-fixed samples of both skin and muscle were blocked in paraffin and $10 \mu$ thick sections were examined after staining with haematoxylin and eosin and, in the majority of cases, with Holmes' silver method for the demonstration of nerve fibres. In all cases, the skin sections were also stained by the Picro-Mallory technique 
TABLE I

Histopathological CHANGES IN AFFECTED MUSCLES

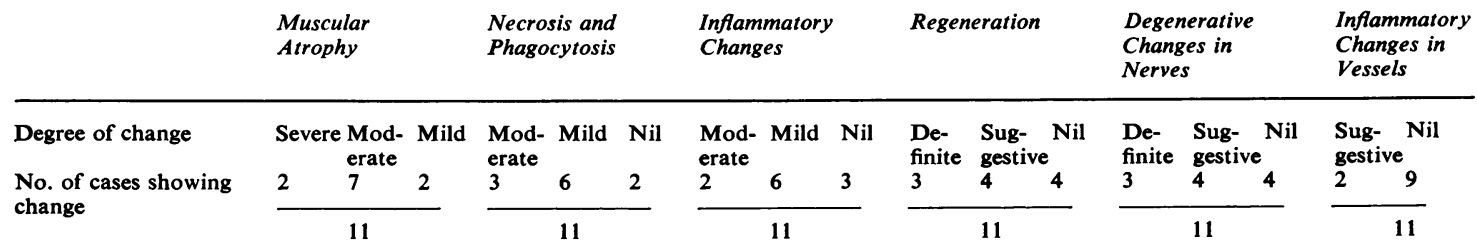

for connective tissues. Wherever possible, both transverse and longitudinal sections of the muscle tissue and sections of the skin from different areas of the specimen supplied were examined.

CHANGES IN MUSCLE The main pathological alterations in muscle, the degree of their severity, and the incidence of their occurrence are presented in Table I. The most constant and noticeable change was muscular atrophy. This generally took the form

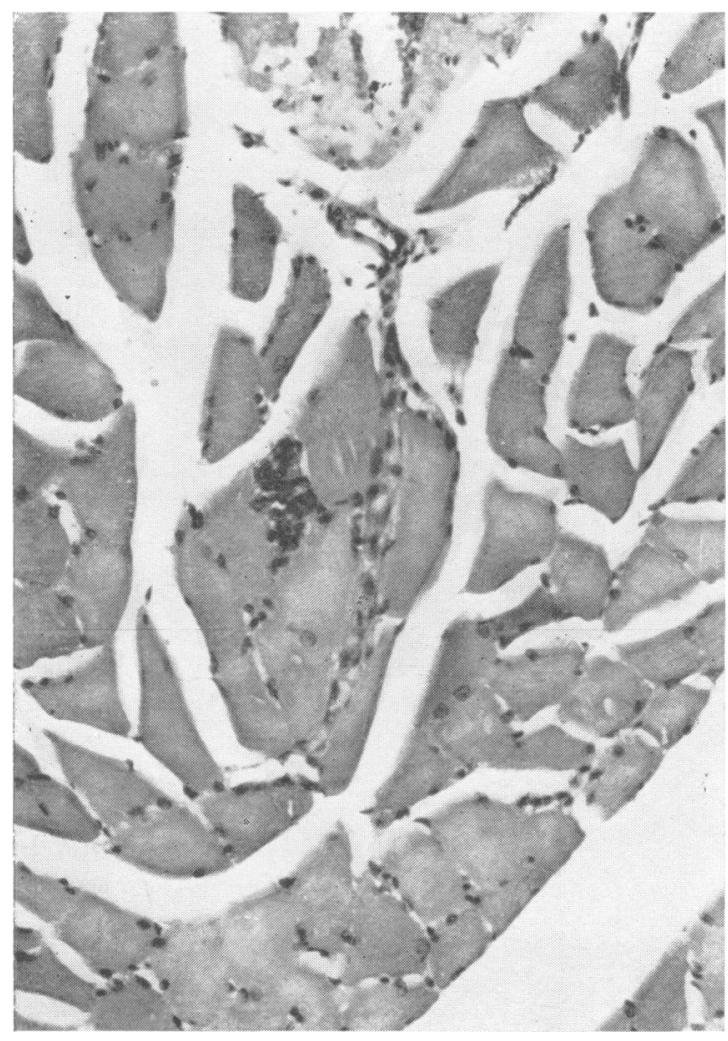

FIG. 1 (NP/A-888). Cross section of muscle fascicles showing generalized atrophy and muscle necrosis of a single fibre with replacement by phagocytes (haematoxylin and eosin $\times 175)$. of a more or less uniform reduction in the size of fibres and also of groups of fibres, e.g., the muscle fasciculi. The extent of atrophy varied from case to case, and in two of the 11 it had involved all the fibre groups within the specimen. The atrophy was accompanied by a variable generalized increase in muscle nuclei, which were generally restricted to the periphery of the muscle fibres.

The second frequent change encountered was necrosis of single or parts of single muscle fibres which showed the disintegration or actual disappearance of muscle substance and its replacement by groups of mononuclear histiocytes (Fig. 1). Entire muscle fasciculi were never found to be necrosed.

Accompanying the muscular atrophy and necrosis there was, in the majority of specimens, a mild to moderate degree of perivascular or interstitial inflammation, small mononuclear cells predominating. In only two instances was there an indication of the perivascular infiltrate affecting the vessel wall, and even here there was no indication of a frank mural necrosis.

Regeneration of muscle fibres when encountered was evidenced by the presence of coarse basophilic fibres with prominent muscle fibrils and sarcolemmal nuclei. The latter appeared more swollen and vesicular than the other nuclei and occasionally revealed clear nucleoli also.

The inter- and intra-fascicular nerve twigs at times showed degenerative changes which generally took the form of an overall increase in the nerve sheath nuclei, and, occasionally, of a pallor and fraying of the nerve twig (Fig. 2a) or a collagenous hyalinization (Figs. 2b and 2c). Inflammatory changes were not seen in any intramuscular nerves. The few muscle spindles that were noticed appeared unremarkable.

There was no appreciable increase in adipose or connective tissue within or around the muscle fascicles in any specimen. In one case a number of muscle fibres showed large 'sarcocysts', but without any reaction and, as shown before (Dastur and Iyer, 1955), of no pathogenic significance. 
CHANGES IN SKIN Small foci of inflammatory cells, around dermal blood vessels (Fig. 3a) or along neurovascular bundles, were more than normally prominent in all the specimens examined. In half of these cases infiltration of the vessel wall by these cells was also encountered (Fig. 3a). The predominant reactive cell was again the small mononuclear, but larger mononuclear cells appearing like histiocytes and suggesting focal necrosis were also not infrequent (Fig. 3b).

The changes (Table II) in the intradermal nerve twigs resembled those observed in the intramuscular nerves but were milder. Early nerve degeneration was again suggested by an irregular increase in the nuclei of the nerve sheaths, indicating internal disorganization (Fig. 3c). In addition there were in a few cases small chronic inflammatory infiltrates, in the form of small mononuclear cell aggregates, within such nerve twigs.

In many of the cases, there were areas of swelling and hyalinization or of diffuse pallor and fragmentation (Fig. 3b) of the dermal collagen. In PicroMallory preparations central pink-staining bands, suggesting fibrinoid degeneration, were observed within the thickened blue collagen bundles. The epidermal keratin was prominent in the majority of the specimens, but this might be related to the site of skin biopsied (the calf) which was an exposed surface in these patients.

There were no alterations in the dermal appendages. In a few specimens prominent clusters of what looked like small, newly formed vascular channels, of the size of arterioles, were seen by the side of the sweat glands.

DISCUssIon The salient histopathological changes observed in these biopsied specimens comprised patchy degeneration of intramuscular and intradermal nerve twigs, early neurogenic muscular atrophy, moderate perivascular inflammation in skin and muscle, especially the former, and occasional collagen degeneration. Of these, the neural changes do not appear inconsistent with those described in the nerve trunks in cases of O.C.P. poisoning and in experimental animals given this compound.
Thus in early cases from the American epidemic, Smith and Lillie (1931) and Burley (1932) had observed non-inflammatory changes in the peripheral nerves. Aring (1942), in an extensive study of the late changes encountered at necropsy in these cases, described neurogenic muscular atrophy, nerve degeneration with heavy overgrowth of endo- and perineural connective tissue, and degeneration of certain long tracts of the spinal cord. The histopathological effects of O.C.P. on nervous tissues of the hen have been studied by Barnes and Denz (1953) and in greater detail by Cavanagh (1954). The latter has stressed the Wallerian nature of the changes observed in the nerves, the varying grades of degeneration in adjacent fibres, and the greater involvement of fibres of larger diameter going into muscular branches. Changes in both axons and myelin progressed from the beginning of the second week to the end of the third, while Schwann cell proliferation became noticeable only towards the end of the second week.

The similarities between the few changes observed in our limited biopsy material and those described above are apparent. Thus, there was more severe evidence of nerve fibre degeneration in relation to the muscle than to the skin; in the same specimen degenerating and normal nerve twigs were frequently found; and biopsy having been performed on our cases between four to six weeks after the onset of the neurological disorder, proliferation of sheath nuclei and of sheath fibres was clearly in evidence (Figs. 2 and 3). Besides the neurogenic type of muscular atrophy, our findings have one other feature in common with those of Aring, namely, a proliferation in clusters of capillaries and small blood vessels, with the difference that we noted this infrequently and only in skin and not in muscle. We do not consider it justifiable, therefore, to assign any significant pathogenetic role to this phenomenon.

A feature of note regarding the histological changes was the evidence of mild collagen degeneration and perivascular inflammation with occasional mural infiltration in the skin, and the necrosis and occasional regeneration of muscle fibres. These are obviously not neurogenic changes, and they point to an 'allergic or hypersensitivity' phenomenon leading

TABLE II

HISTOPATHOLOGICAL CHANGES IN SKIN

\begin{tabular}{|c|c|c|c|c|c|c|c|c|c|c|c|}
\hline \multirow{4}{*}{$\begin{array}{l}\text { Degree of change } \\
\text { No. of cases showing } \\
\text { change }\end{array}$} & \multicolumn{3}{|c|}{$\begin{array}{l}\text { Degeneration or } \\
\text { Hyalinization of Collagen }\end{array}$} & \multicolumn{2}{|c|}{$\begin{array}{l}\text { Degeneration or } \\
\text { Inflammation of Vessel } \\
\text { Walls }\end{array}$} & \multicolumn{3}{|c|}{ Perivascular Inflammation } & \multicolumn{3}{|c|}{$\begin{array}{l}\text { Degenerative or } \\
\text { Inflammatory Changes in } \\
\text { Cutaneous Nerves }\end{array}$} \\
\hline & Definite & \multirow{2}{*}{$\begin{array}{l}\text { Sug- } \\
\text { gestive } \\
5\end{array}$} & \multirow{2}{*}{$\begin{array}{l}\text { Nil } \\
4\end{array}$} & Moderate Mild & \multirow{2}{*}{$\begin{array}{l}\text { Nil } \\
7\end{array}$} & Severe & Moderate & Mild & Definite & \multirow{2}{*}{$\begin{array}{l}\text { Sug- } \\
\text { gestive } \\
9\end{array}$} & \multirow{2}{*}{$\begin{array}{l}\text { Nil } \\
2\end{array}$} \\
\hline & 5 & & & 4 & & 0 & 10 & 4 & 3 & & \\
\hline & \multicolumn{3}{|c|}{14} & \multicolumn{2}{|l|}{14} & \multicolumn{3}{|c|}{14} & \multicolumn{3}{|c|}{14} \\
\hline
\end{tabular}




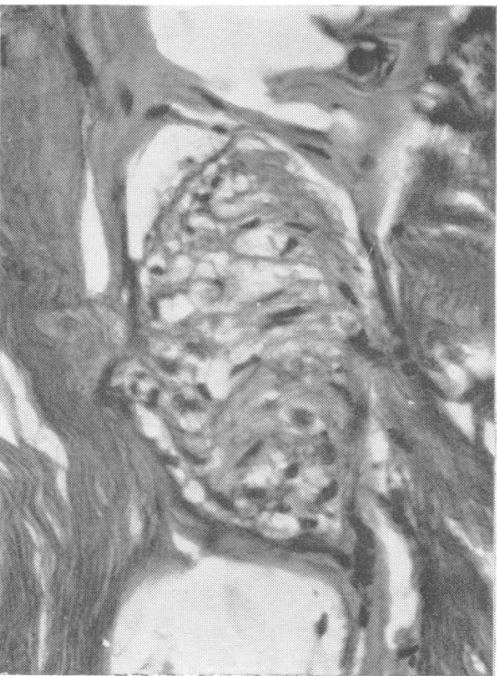

FIG. 2a

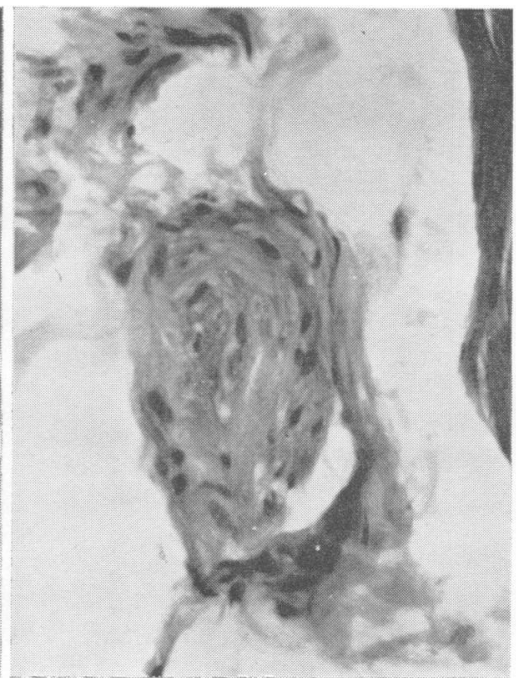

FIG. $2 b$

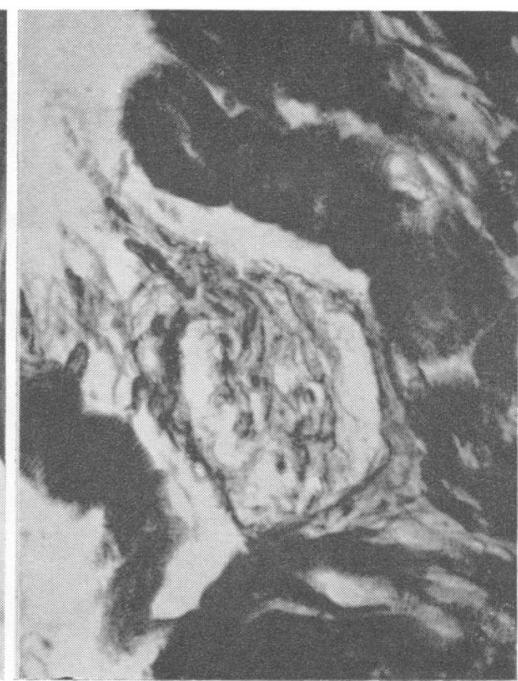

FIG. 2c

FIG. 2. (NP/A-892, 896). Interfascicular nerve twigs showing (a) rarefaction and vacuolation, (b) hyalinization of nerve sheath elements, and (c) loss of nerve fibres (a and b, haematoxylin and eosin, c, Holmes's silver stain; each $\times 385)$.

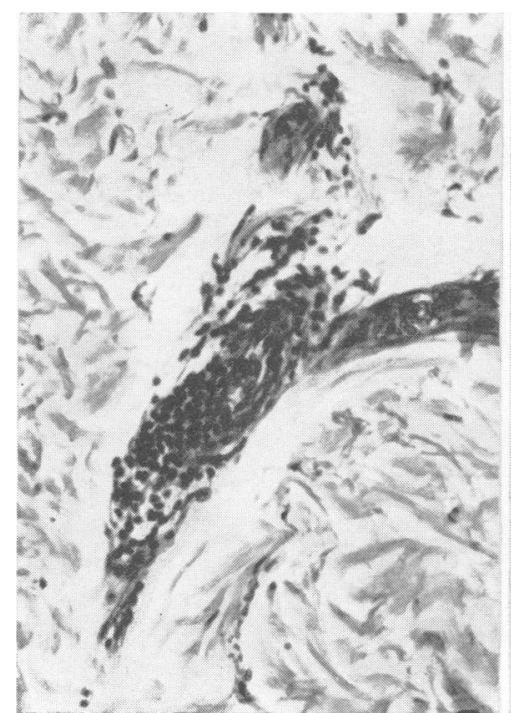

FIG. 3a

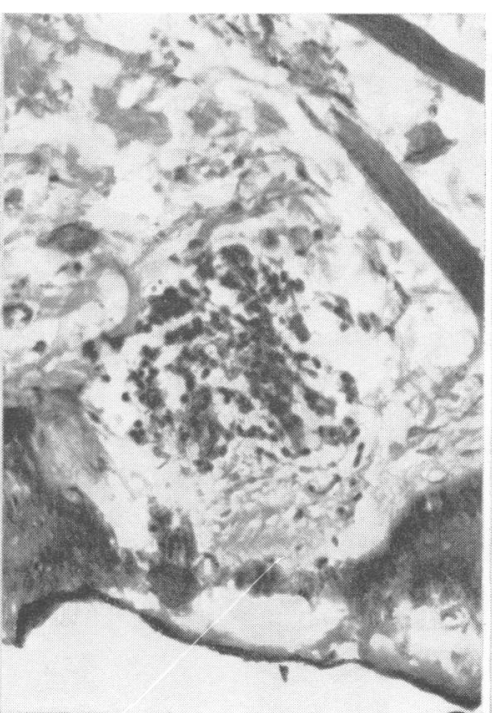

FIG. $3 b$

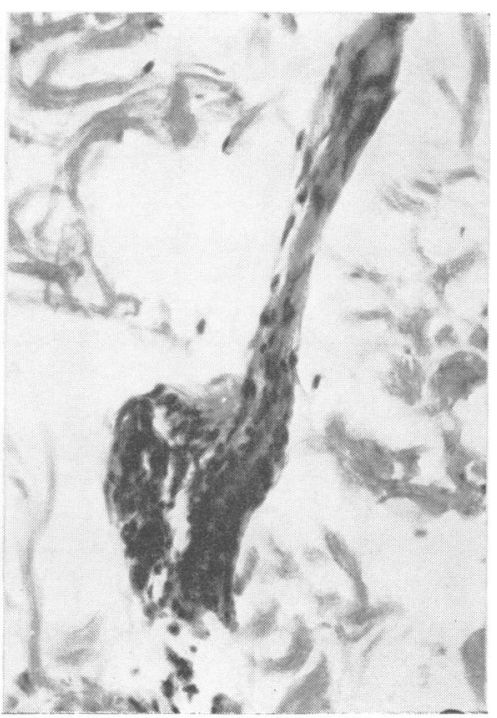

FIG. 3c

FIG. 3a (NP/A-892). Dermal blood vessel showing perivascular and intramural infiltration with small mononuclear cells. FIG. 3b. (NP/A-884). Subepidermal focus of small and round, and irregularly shaped mononuclear cells, together with collagen fragmentation.

FIG. 3c (NP/A-888). Neurovascular bundle in dermis showing proliferation of sheath nuclei of the nerve twig and of the vessel wall nuclei.

(Fig. 3a-3c haematoxylin and eosin $\times 175$ ) 
to a chronic polymyositis or dermatomyositis type of picture (Walton and Adams, 1958). The recent interesting observation of Glees (1960) that administration of cortisone, together with or after an application of O.C.P. to the comb of the hen, prevented the onset of paralysis or, if paralysis had already set in, reduced the bird to a mild state of postural imbalance, appears to point in the same direction.

\section{CHANGES IN BLOOD CHOLINESTERASE}

Determinations of cholinesterase were made on blood samples obtained from seven of the patients admitted to hospital in late January 1960. Two among this group of patients (1369 and 1371, batch I) as well as two others admitted late in May 1960 (7718 and 7811, batch II) were followed up for several months. For the four cases where serial determinations were possible, the cholinesterase of plasma and of erythrocytes was determined periodically in blood samples collected once a month.

METHOD Determinations of cholinesterase were carried out by the manometric method using the Warburg apparatus (Ammon, 1933). The values obtained give a measure of the relative level of cholinesterase in the samples compared with the standards under identical conditions. The standard controls consisted of freshly drawn blood from normal healthy individuals.

RESULTS AND DISCUSSION As is well known the plasma cholinesterase is the non-specific or pseudocholinesterase, whereas the cholinesterase of erythrocytes, according to most evidence, is identical with the enzyme hydrolysing acetylcholine in brain tissue. The average results of determinations of plasma cholinesterase and the erythrocyte cholinesterase in the initial blood samples from nine cases are given in Table III. It is evident that there is a considerable diminution in the erythrocyte (true) cholinesterase whereas the values for the plasma enzyme show a rise in the patients compared with that in controls.

The result of serial determinations carried out on two batches of patients admitted to the hospital at different times is illustrated in Fig. 4. It is apparent that the erythrocyte cholinesterase was reduced to a greater extent in the second group. It is also to be noted that the reduction is considerable and occurs quite soon after the onset of clinical symptoms. The rise in the plasma cholinesterase in the initial samples of blood from the first batch of patients is found to be higher than the corresponding values of the second batch. Considering the fact that in the first batch of patients the samples of blood were withdrawn after they had been in hospital for about a month, whereas in the second batch blood was taken after only 10 days, it appears that the increase in the plasma enzyme occurs after a period in the course of the disease. In conformity with this view, it is seen that the plasma cholinesterase values of the second batch are found to be higher in the subsequent determinations.

It is clear from the pattern of results of serial determinations carried out on four patients that the two enzymes studied tend to converge to within normal limits after about three months. Thus, the erythrocyte cholinesterase, which is reduced by more than $50 \%$ shortly after the onset of clinical symptoms, rises gradually and reaches the normal range of values after three months. The plasma cholinesterase shows a transient increase reaching a maximum in about a month and then gradually decreases, reaching the normal limits after a period of three to six months.

Although there are numerous studies pertaining to changes in blood cholinesterase in O.C.P. toxicity and other conditions producing similar clinical symptoms, the correlation of cholinesterase changes with neuromuscular lesions is not at all clear. In two cases of poisoning by an organic phosphorus insecticide (bismonoisopropyl amine fluorophosphine oxide, Mipafox) Bidstrup, Bonnel, and Beckett (1953) found that the plasma and erythrocyte cholinesterases were considerably decreased. Addition of O.C.P. in vitro to human nerve tissue or serum has been found to inhibit pseudocholinesterase 75 to $99 \%$, causing only 7 to $10 \%$ inhibition of true cholinesterase (Earl and Thompson, 1952). The effect on tissues of experimental animals was found to be less. Mendel and Rudney (1944) have, however,

TABLE III

ACETYLCHOLINESTERASE ACTIVITY OF INITIAL SAMPLES OF BLOOD

\begin{tabular}{|c|c|c|c|c|c|}
\hline \multirow[t]{2}{*}{ Subject } & \multirow[t]{2}{*}{ Total No. } & \multicolumn{2}{|c|}{ Plasma $\left(\mu l . \mathrm{CO}_{2} / 20 \mathrm{~min}.\right)$} & \multicolumn{2}{|c|}{ R.B.C. $\left(\mu l . \mathrm{CO}_{2} / 20 \mathrm{~min}.\right)$} \\
\hline & & Average & Range & Average & Range \\
\hline $\begin{array}{l}\text { Normal } \\
\text { Patients of batch I } \\
\text { Patients of batch II }\end{array}$ & $\begin{array}{l}8 \\
7 \\
2\end{array}$ & $\begin{array}{l}54 \cdot 5 \\
81 \\
64\end{array}$ & $\begin{array}{l}41-69 \\
72-88 \\
60-68\end{array}$ & $\begin{array}{l}178 \cdot 5 \\
119 \\
84\end{array}$ & $\begin{array}{c}156-193 \\
103-139 \\
77-91\end{array}$ \\
\hline
\end{tabular}




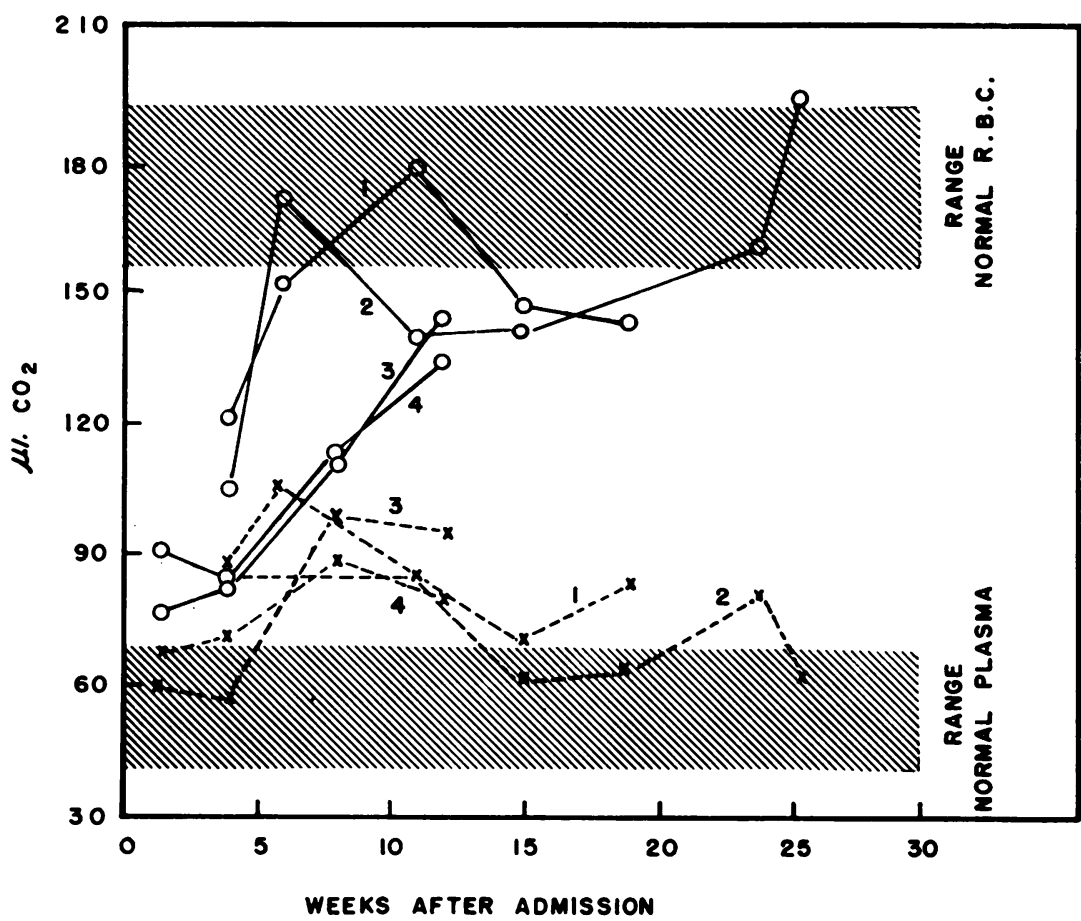

FIG. 4. Acetylcholinesterase activity of blood. $\bigcirc-\bigcirc$ red blood cells, $\times$ - - $\times$ plasma.

1, Case 1369; 2, Case 1371; 3 , Case 7811; 4, Case 7718.

reported that oral administration of O.C.P. to rats produced an $80 \%$ decrease in the pseudocholinesterase and had no effect on the true cholinesterase.

According to the meagre data on blood cholinesterase reported from Morocco (Geoffroy, Pascal, Slomic, and Benebadji, 1960), the pseudocholinesterase was found to be lowered during the first three months. Actual values given for three cases before and after treatment with pilocarpine, which is reported to have produced clinical improvement, show, however, that erythrocyte cholinesterase is increased on treatment and pseudocholinesterase is diminished. These results are qualitatively in the direction observed in the present studies. During the acute phase of the disease the plasma cholinesterase was high and erythrocyte cholinesterase was very significantly decreased. With progress of treatment and amelioration of the clinical condition the cholinesterase values tended to converge towards the normal.

The physiological significance of the non-specific cholinesterase is not established. Experiments on nerve degeneration with chickens (Cavanagh, Thompson, and Webster, 1954) indicate that the pseudocholinesterase is a component of the Schwann cells of the nerve. On nerve section, the true cholinesterase was reduced to zero, whereas the pseudocholinesterase showed a striking increase after a pericd, and then returned to normal limits. The suggestion has been made that this transient increase may be associated with the active multiplication of Schwann cells in the degenerating nerve. It is possible that the increase in pseudocholinesterase observed in the present study may also be associated with a similar phenomenon. It is of interest in this connexion that the histopathological findings reported in the present study show that in some of the cases in which the pseudocholinesterase level was raised, there was also evidence of nerve fibre degeneration and regeneration with proliferation of sheath nuclei. The data on human material are, however, yet too meagre to correlate the changes in blood cholinesterase with the neurological lesions in O.C.P. poisoning.

\section{SUMMARY}

This paper reports a detailed investigation on 32 of 58 cases of toxic polyneuritis encountered in Bombay city in 1960. Evidence has been presented to show that toxicity was due to ortho-cresyl-phosphate present as a contaminant of mustard oil used for cooking.

The clinical features were similar to those reported in previous epidemics of O.C.P. poisoning. All cases showed that the distal groups of muscles 
were mainly affected, causing unsteadiness on standing and a high-stepping, lurching gait. There was also a glove and stocking type of sensory impairment in the majority of cases, a finding not encountered frequently in previous outbreaks elsewhere.

Histological examination of skin and muscle samples removed at biopsy in 14 of the 32 cases showed moderate neurogenic muscular atrophy, with degenerative changes in the intramuscular and intradermal nerve twigs, findings corroborating earlier observations on nerve trunks. However, concurrent changes of muscle fibre necrosis and occasional regeneration, together with frequent alterations in the dermal collagen and mild chronic perivascular inflammation in the skin and the muscle, suggested a 'hypersensitivity' type of reaction also.

Determination of blood cholinesterase levels carried out on nine of the patients admitted to hospital has demonstrated that the plasma cholinesterase was increased after a month in the course of the disease. The erythrocyte cholinesterase level was considerably diminished (50\%) quite early after the onset of the clinical symptoms. Both the plasma and erythrocyte cholinesterase activities returned to normal levels after about three months.

Our thanks are due to Dr. V. S. Shevade, officiating superintendent, Lokmanya Tilak Municipal General Hospital, and to Dr. V. R. Khanolkar, Director, Indian Cancer Research Centre. We are grateful to Professor P. V. Gharpure, Officer-in-Charge, I.C.M.R. Polio Research Unit, Bombay, for the virological studies; to Dr. V. Sadashivan, analyst, Bombay Municipality, for analysis of samples of oil; to Dr. A. R. Shirodkar, assistant health officer, Bombay Municipality, for epidemiological investigations; to Drs. K. N. Desai and V. M. Mandlekar of the Lokmanya Tilak Municipal General Hospital, for clinical assistance; and to Mr. P. B. Nath, of I.C.M.R. Neurology Unit, for assistance with histopathological techniques.

\section{REFERENCES}

Ammon, R. (1933). Pflügers Arch. ges. Physiol., 233, 486.

Aring, C. D. (1942). Brain, 65, 34.

Barnes, J. M., and Denz, F. A. (1953). J. Path. Bact., 65, 597.

Bidstrup, P. L., Bonnel, J. A., and Beckett, A. G. (1953). Brit. med. J., $1,1068$.

Burley, B. T. (1932). J. Amer. med. Ass., 98, 298.

Cavanagh, J. B. (1954). J. Neurol. Neurosurg. Psychiat., 17, 163.

-, Thompson, R. H. S., and Webster, G. R. (1954). Quart. J. exp. Physiol., 39, 185.

Dastur, D. K., and Iyer, C. G. S. (1955). Neurology (Madras), 2, 25. Earl, C. J., and Thompson, R. H. S. (1952). Brit. J. Pharmacol., 7, 261 .

Geoffroy, H., Pascal, P., Slomic, A., and Benebadji, M. (1960). Presse méd., 68, 1474.

Glees, P. (1960). Nature (Lond.), 187, 327.

Guttmann, L. (1932). Med. Klin., 28, 716.

Hotston, R. D. (1946). Lancet, 1, 207.

Humpe, F. (1942). Münch. med. Wschr., 89, 448. Abstracted in Bull. Hyg. (Lond.) 17, 795.

Hunter, D. (1955). The Diseases of Occupations. English Universities Press, London.

(1956). In Price's Practice of Medicine, 9th ed., ed. D. Hunter, p. 379. Oxford University Press, London.

Jordi, A. U. (1952). J. Aviat. Med., 23, 623.

Mendel, B., and Rudney. H. (1944). Science, 100, 499.

Sampson, B. F. (1942). S. Afr. med. J., 16, 1. Abstracted in Bull. Hyg. (Lond.), 17, 647.

Smith, H. V., Spalding, J. M. K. (1959) Lancet 2, 1019.

Smith, M. I., Elvove, E., and Frazier, W. H. (1930). Publ. Hlth Rep. (Wash.), 45, 2509.

- , and Lillie, R. D. (1931). Arch. Neurol. Psychiat. (Chicago), 26, 976.

Walton, J. N., and Adams, R. D. (1958). Polymyositis, p. 187. Livingstone, Edinburgh and London. 